\title{
Seasonal incidence of coarctation of the aorta ${ }^{1}$
}

\author{
Olli S. Miettinen, M. Lawrence Reiner, and Alexander S. Nadas \\ From the Cardiology Division, Children's Hospital Medical Center, Harvard Medical \\ School, and Harvard School of Public Health, Boston, Massachusetts, U.S.A.
}

On the basis of 560 consecutive cases of coarctation of the aorta it is shown that the incidence of this anomaly has a seasonal variation, implying the existence of exogenous aetiological factors. The pattern of births with coarctation apparently has two seasonal peaks in the New England area, one in September-November and the other in fanuary-March, and as cases born in these two periods have different distributions by location of the coarctation and, independently, different frequencies of complicating cardiovascular anomalies, it seems that different aetiological factors are involved.

The causes of coarctation of the aorta remain almost totally unknown. The involvement of a genetic mechanism is suggested by the frequent occurrence of this anomaly in patients with Turner's syndrome (Wilkins and Fleischmann, 1944), while next to nothing is known about possible exogenous factors (Campbell and Polani, I96I; Morgan, 1969).

One approach to the detection of exogenous aetiology in congenital defects is to examine the seasonal distribution of births of affected children (Bailar and Gurian, 1965, 1967). This approach was used by Rutstein, Nickerson, and Heald (1952) in demonstrating the role of rubella in the aetiology of persistent ductus arteriosus. These authors also explored the seasonal incidence of coarctation, but, with only 77 cases, no conclusion could be reached. Campbell and Polani (1961) examined data from 151 cases, and found an indication of a seasonal pattern, which, however, was not statistically significant. It was felt that the observed seasonal differences were 'real', but the need for confirmatory data was emphasized.

In the present work the seasonal incidence of coarctation was explored in a substantially larger series, and it was possible to characterize the seasonal incidence in relation to sex, associated anomalies, and even location of the coarctation.

Received 19 July 1969.

1 Supported by grants from the National Heart Institute and the National Institute for General Medical Sciences, National Institutes of Health, United States Public Health Service.

\section{Subjects and methods}

Included in the present study were all cases of coarctation of the thoracic aorta diagnosed at Children's Hospital Medical Center, Boston, from I950 to the end of 1965 . Case records were reviewed by one of us (M.L.R.), and information was obtained on date and place of birth, sex, age at first examination in our clinic, location of coarctation (proximal, opposite, or distal to the ductus arteriosus), and presence or absence of associated cardiovascular anomalies.

The 'expected' distribution of cases by month of birth was derived for the group born in the New England area since 1930. These cases were first distributed by state and year of birth, and then for each state-year-specific subgroup the corresponding distribution of all live births by month was obtained from published vital statistics. The contribution of each state-year-specific subgroup to the expected monthly frequencies of patient births was then computed as the product of the size of that subgroup and the corresponding proportion of all live births. These state-yearspecific expected distributions were then summated to obtain the expected number of patient births for each month. From the resulting expected frequencies for each month, the following expected proportions of patient births in the successive months from January to December were obtained: $0.0809,0.0766,0.0852,0.0820,0.084 \mathrm{I}, 0.834$, $0.0882,0.0873,0.0857,0.0852,0.0798$, and 0.0814 . In all analyses involving monthly expected numbers of births, such numbers were derived by multiplication of these proportions by the total number of patients in the group being analysed.

\section{Results}

General characteristics of study series The review of hospital records yielded a total 
of 560 cases of coarctation. In 527 patients the diagnosis had been confirmed at catheterization (aortography), operation, and/or necropsy. The age at first examination in our clinic ranged from 0.0 to 50.0 years, with a median of 8.4 years. There was a total of 344 male and 216 female cases, male cases thus predominating by a ratio of $\mathrm{I} \cdot 59$ to $\mathrm{I}(6 \mathrm{I} \% \mathrm{male})$.

Location of the coarctation had been explicitly recorded for 358 cases. The frequencies of locations proximal, opposite, and distal to the ductus arteriosus (ligamentum arteriosum) were 180 (50\%), 59 (16\%), and $119(33 \%)$, respectively. In the majority of the remaining 202 cases the records indicated that the coarctation was in the 'usual' location which in all probability means distal to the ductus. Indeed, an analysis of the age and sex distributions and the frequency of complications, given in Table $I$, shows that this group of 202 cases has the characteristics of cases with postductal coarctation. It thus seems reasonable to conclude that in the total series the frequencies of preductal, juxtaductal, and postductal coarctations were 180 ( $32 \%)$, 59 (1 I \%), and 321 ( $57 \%)$, respectively.

Distribution by month of birth For the total group of 560 cases the distribution by month of birth is shown in Fig. IA. There is seen to be a deficiency of births from April to August. The variation is small and also statistically unimpressive $(p=0.05)$.

In an effort to obtain an aetiologically more homogeneous group of cases, consideration was first given to exclusion of all patients with an associated persistent ductus arteriosus, 124 in number. Some cases of associated persistent ductus may be sequelae of coarctation, but there is the possibility that the aetiology of some cases of the combined syndrome is
TABLE I Age, sex ratio, and frequency of complications, by location of coarctation

\begin{tabular}{|c|c|c|c|c|c|c|}
\hline \multirow{3}{*}{$\begin{array}{l}\text { Location of } \\
\text { coarctation }\end{array}$} & \multirow{3}{*}{ No. } & \multicolumn{2}{|c|}{ Age (yr.) } & \multirow{3}{*}{$\begin{array}{l}\text { Male- } \\
\text { female } \\
\text { ratio }\end{array}$} & \multirow{2}{*}{\multicolumn{2}{|c|}{$\begin{array}{l}\% \text { With cardio- } \\
\text { vascular } \\
\text { complications }\end{array}$}} \\
\hline & & \multirow{2}{*}{ Range } & \multirow{2}{*}{ Median } & & & \\
\hline & & & & & $P D A$ & Any \\
\hline $\begin{array}{l}\text { Proximal to duct } \\
\text { Opposite to duct } \\
\text { Distal to duct } \\
\text { Not explicitly stated }\end{array}$ & $\begin{array}{r}180 \\
59 \\
119 \\
202\end{array}$ & $\begin{array}{l}0.0-50 \\
0.0-46 \\
0.0-46 \\
0.0-47\end{array}$ & $\begin{array}{r}0.5 \\
9 \cdot 0 \\
11 \cdot 3 \\
10 \cdot 0\end{array}$ & $\begin{array}{l}I \cdot I 4 \\
3 \cdot 21 \\
I \cdot 64 \\
I \cdot 77\end{array}$ & $\begin{array}{l}48 \cdot 3^{\star} \\
23 \cdot 7 \\
9 \cdot 2 \\
5 \cdot 4\end{array}$ & $\begin{array}{l}68 \cdot 0 \\
37 \cdot 3 \\
28 \cdot 6 \\
23 \cdot 3\end{array}$ \\
\hline Total & 560 & $0.0-50$ & $8 \cdot 4$ & I.59 & $2 I \cdot I$ & 40.5 \\
\hline
\end{tabular}

PDA $=$ persistent ductus arteriosus.

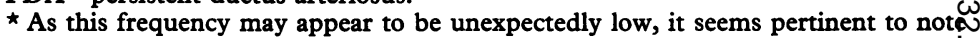
that it was lowest, $9 / 6 \mathrm{I}=15 \%$, in cases with clinical diagnosis confirmed only at operation (median age $7.8 \mathrm{yr}$.), while in necropsied cases (median age $0.0 \mathrm{yr}$. the frequency of persistent ductus was $57 / 74=77 \%$.

similar to that of solitary persistent ductus. Thus the seasonal pattern of coarctation in the total group might be confounded by some cases having the seasonal incidence characteristic of persistent ductus. The seasonal distribution of the 436 cases remaining after removal of all cases with persistent ductus is shown in Fig. IB. The ordinary $\chi^{2}$ test based on the monthly frequencies gives $p=0.003$, though this test is insensitive in the detection of seasonal patterns (Edwards, I96I).

Seasonal incidence was then explored separately for male and female cases, particularly since Campbell and Polani (I96I) have suggested that the seasonal patterns may be different for the two sexes. There were 159 female cases without persistent ductus. For them, a comparison of the monthly observed and expected frequencies suggests an excess of observed cases in March and a deficiency in August (the observed-to-expected ratios were $21 / 13.6$ and 6/13.9, respectively), but a $\chi^{2}$ test

FIG. I The ratio of observed to expected number of cases of coarctation born in each month is shown for the total series $(A)$ and for successively 'purified' subseries $(B-E)$.

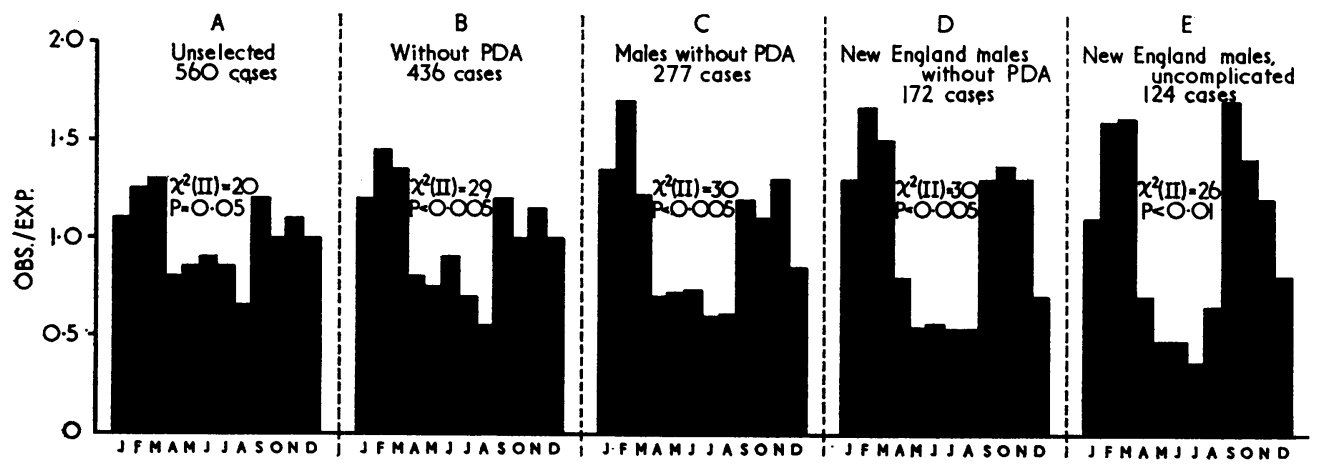


based on the monthly frequencies yields $p>0.30$. The pattern is such that other statistical tests (Edwards, 196I) cannot be expected to be much more sensitive. Even the a posteriori comparison of the 'low season' of AprilAugust (59 observed cases with 67.6 'expected') to the rest of the year, suggested by Fig. IB, does not approach (nominal) significance at the customary $5 \%$ level. The data therefore give no statistical confirmation of the existence of seasonal variation in the risk of coarctation in the female. The pattern for the group of 277 male cases without persistent ductus is shown in Fig. IC. Here the $p$ value from the $\chi^{2}$ test is 0.002 , so that there is very good evidence of the existence of seasonal variation in the risk. Direct statistical comparison of the seasonal distributions between the two sexes, however, does not yield any good indication of difference, and its existence, therefore, remains unsettled.

Since factors influencing seasonal distribution may vary by region, it was thought possible that the seasonal variation might be brought into sharper focus by considering a limited geographical area. Thus, cases born outside New England were removed from the series of male patients without persistent ductus. The pattern for the remaining 172 cases was indeed more pronounced, as is seen in Fig. ID.

Finally, consideration was given to the possibility that the specific aetiology of coarctation is most clearly reflected by uncomplicated cases. The pattern for the $124 \mathrm{New}$ England born male cases without associated cardiovascular anomalies, depicted in Fig. IE, seems to bear this out.
The detailed data on monthly frequencies of births in relation to the location of the anomaly, presence of persistent ductus, and sex are given in Table 2.

Duality of aetiology An examination of the pattern that emerged from the above analyses suggests that the seasonal incidence of coarctation in the male may be characterized by two peaks, one in September-November and the other in January-March. This, in turn, suggests that two different exogenous mechanisms of aetiology may be involved, because any given factor - whether viral, nutritional, or whatever else - generally has only a single seasonal cycle. The existence of two concentrations of different aetiological factors would be strongly supported by evidence indicating that cases born in the two periods of high incidence have different characteristics. Such a comparison was made with respect to type of coarctation and frequency of complicating cardiovascular anomalies, basing the analyses on male patients without persistent ductus.

The data are given in Table 3 and depicted in Fig. 2. There were 83 male cases without persistent ductus born in September-November and 95 born in January-March. The frequencies of locations proximal, opposite, and distal to the ductus arteriosus for the cases born in September-November were 24 (29\%), $4(5 \%)$, and $55(66 \%)$, respectively, while for January-March the corresponding frequencies were 14 ( $15 \%)$, I6 (I7\%), and 65 (68\%). The $\chi^{2}$ test ( 2 d.f.) gives $\mathrm{p}<0.02$. The over-all frequencies of complications in SeptemberNovember and January-March were 14/83=

TABLE 2 Monthly frequencies of births in 560 cases of coarctation in relation to the location of the anomaly, associated persistent ductus, and sex

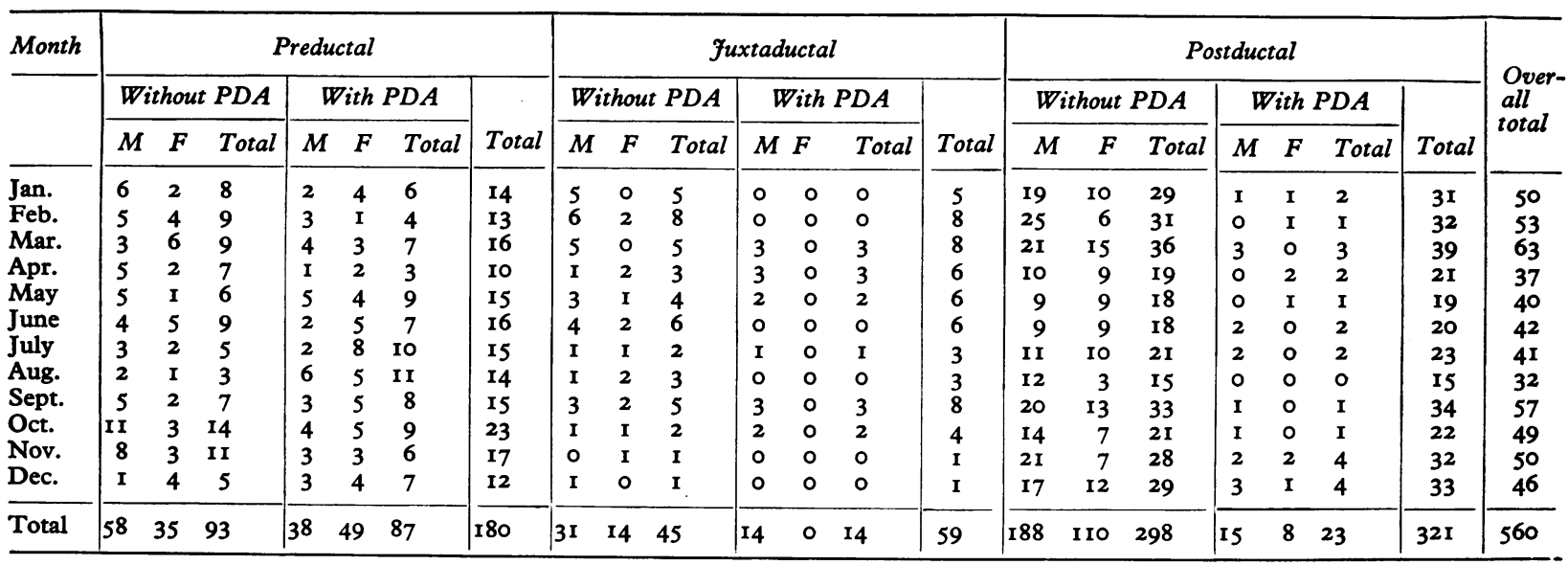




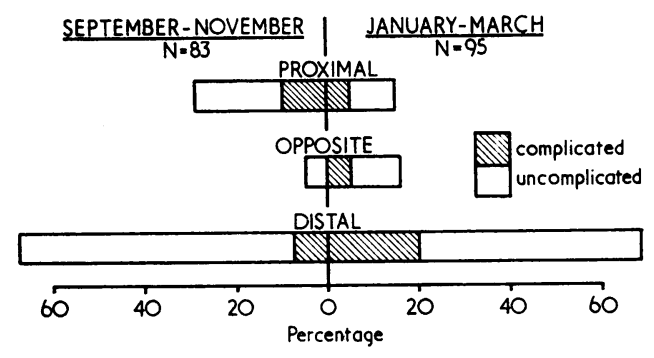

FIG. 2 Comparison of cases of coarctation born in the two seasons of high incidence with respect to location of coarctation and frequency of associated cardiovascular anomalies. Both comparisons show statistically significant differences $(p<0.05)$.

17 per cent and $29 / 95=31$ per cent, respectively, a difference for which the $p$ value from the usual $\chi^{2}$ test is 0.03 . This comparison, however, is confounded by the above difference in type of coarctation and the relation between location of coarctation and the frequency of complications. Making the comparison within each type of coarctation and pooling the information in terms of the Mantel-Haenszel (1959) test procedure yields $\mathrm{p}<0.02$.

It seems fair to conclude that, in the category of male cases without persistent ductus arteriosus, those born during the SeptemberNovember peak have a lower frequency of associated cardiovascular anomalies, and, independently, a higher frequency of sites proximal to the ductus relative to sites opposite to it. This suggests that there indeed are two seasonal peaks reflecting respective concentrations of two different exogenous aetiological influences.

\section{Discussion}

Despite extensive research, the existence of substantial seasonal variation in incidence has thus far been well established for only three congenital anomalies: persistent ductus arteriosus (Rutstein et al., 1952), anencephaly (McKeown and Record, I95I), and congenital dislocation of the hip (Nagura, 1955). These anomalies share yet another unusual characteristic, namely, that of being more common in women than in men. The present study, confirming a suggestion by Campbell and Polani (196I), shows seasonal variation in the incidence of coarctation of the aorta - a defect with male predominance.

By indicating that there is a significant exogenous component of aetiology, the detection of seasonal variations of incidence raises hope
TABLE 3 Location of coarctation and frequency of associated cardiovascular anomalies in male cases without persistent ductus arteriosus

\begin{tabular}{|c|c|c|c|c|c|c|c|c|c|}
\hline \multirow{4}{*}{$\begin{array}{l}\text { Location of } \\
\text { coarctation }\end{array}$} & \multicolumn{9}{|c|}{ Season of birth } \\
\hline & \multicolumn{3}{|c|}{ Sept.-Nov. } & \multicolumn{3}{|c|}{ fan.-March } & \multicolumn{3}{|c|}{ All months } \\
\hline & \multicolumn{2}{|c|}{ Complications } & \multirow[b]{2}{*}{ Total } & \multicolumn{2}{|c|}{ Complications } & \multirow[b]{2}{*}{ Total } & \multicolumn{2}{|c|}{ Complications } & \multirow[b]{2}{*}{ Totai } \\
\hline & + & - & & + & - & & + & - & \\
\hline $\begin{array}{l}\text { Proximal to duct } \\
\text { Opposite to duct } \\
\text { Distal to duct }\end{array}$ & $\begin{array}{l}8 \\
0 \\
6\end{array}$ & $\begin{array}{r}16 \\
4 \\
49\end{array}$ & $\begin{array}{r}24 \\
4 \\
55\end{array}$ & $\begin{array}{r}5 \\
5 \\
19\end{array}$ & $\begin{array}{r}9 \\
11 \\
46\end{array}$ & $\begin{array}{l}14 \\
16 \\
65\end{array}$ & $\begin{array}{r}25 \\
5 \\
36\end{array}$ & $\begin{array}{r}33 \\
26 \\
152\end{array}$ & $\begin{array}{r}58 \\
31 \\
188\end{array}$ \\
\hline Total & 14 & 69 & 83 & 29 & 66 & 95 & 66 & 2 II & 277 \\
\hline
\end{tabular}

of prevention. The attainment of this practical goal generally requires an understanding of what the variation is in the environment that the incidence pattern reflects. In persistent ductus it seems to be largely the variation in the incidence of rubella (Rutstein et al., 1952; Campbell, 1961), and passive immunization as well as therapeutic abortion are being practised in cases of rubella in early pregnancy. No such breakthrough has yet been achieved in regard to anencephaly or congenital dislocation of the hip.

As to the explanation of the seasonal incidence pattern of coarctation, it seems that rubella is not involved to any significant extent (Campbell, I96I). Yet, major consideration should still be given to other viral infections during organogenesis, inasmuch as they can have teratogenic effects (Brown, 1966; Jackson, 1968) and are generally characterized by marked seasonal variation of incidence. $\mathrm{Re}-$ search in this area should concentrate on infections peaking in February-April or JuneAugust. A useful approach seems to be that based on the determination of antibody titres in mothers of affected babies (Brown and Evans, 1967).

Very little is known about seasonal variation in the intake of drugs among mothers in their early pregnancy, but it seems relevant to note that coarctation is among the anomalies caused by thalidomide (Smithells, 1966). Nutritional factors and, in the same vein, exposure to ultraviolet light have obvious seasonal variations, but their relavance in the aetiology of congenital cardiovascular anomalies in man remains a matter of conjecture. However, the observation that a diet deficient in vitamin A leads to anomalies of the aortic arch in the offspring of the rat (Wilson and Warkany, 1949) is noteworthy. 


\section{References}

Bailar, J. C., and Gurian, J. (1965). Congenital malformations and season of birth: a brief review. Eugenics Quarterly, 12, 146.

$\longrightarrow$, and - (1967). The medical significance of date of birth. Eugenics Quarterly, 14, 89.

Brown, G. C. (1966). Recent advances in the viral aetiology of congenital anomalies. In Advances in Teratology, Vol. I, p. 55. Ed. by D. H. M. Woollam. Logos Press, London.

- , and Evans, T. N. (1967). Serologic evidence of coxsackie-virus etiology of congenital heart disease. Fournal of the American Medical Association, 199, 183.

Campbell, M. (196I). Place of maternal rubella in the aetiology of congenital heart disease. British Medical fournal, $1,691$.

- , and Polani, P. E. (196r). The aetiology of coarctation of the aorta. Lancet, I, 463.

Edwards, J. H. (196r). The recognition and estimation of cyclic trends. Annals of Human Genetics, 25, 83.

Jackson, B. T. (1968). The pathogenesis of congenital cardiovascular anomalies. New England fournal of Medicine, 279, 25 and 80.

McKeown, T., and Record, R. G. (I95I). Seasonal incidence of congenital malformations of the central nervous system. Lancet, $1,192$.

Mantel, N., and Haenszel, W. (1959). Statistical aspects of the analysis of data from retrospective studies of disease. Fournal of the National Cancer Institute, 22, 719.

Morgan, J., (1969). Evidence of non-genetic origin of coarctation of the aorta. Canadian Medical Association fournal, 100, 1134.

Nagura, S. (1955). Zur Àtiologie der angeborenen Hüftverrenkung. Zentralblatt für Chirurgie, 80, 1933.

Rutstein, D. D., Nickerson, R. J., and Heald, F. P. (1952). Seasonal incidence of patent ductus arteriosus and maternal rubella. American fournal of Diseases of Children, 84, 199.

Smithells, R. W. (1966). Drugs and human malformations. In Advances in Teratology, Vol. I, p. 25I. Ed. by D. H. M. Wollam. Logos Press, London.

Wilkins, L., and Fleischmann, W. (1944). Ovarian agenesis; pathology, associated clinical symptoms and the bearing on the theories of sex differentiation. Fournal of Clinical Endocrinology and Metabolism, 4, 357.

Wilson, J. G., and Warkany, J. (1949). Aortic-arch and cardiac anomalies in the offspring of vitamin A deficient rats. American fournal of Anatomy, 85, 113. 